\title{
Liquid chromatography mass spectrometry Profile and In vitro Antimicrobial Potentials of Mentha piperita (Mint) Hexane Extract on some Food-borne pathogens
}

\author{
Musa Bashir*1 and Ruqayyah A. Usman ${ }^{2}$ \\ 1. Centre for Dryland Agriculture, Bayero University, Kano-Nigeria. \\ 2. Department of Microbiology, Faculty of Life Science, Bayero University, Kano-Nigeria. \\ *Corresponding Author: Musa Bashir; mbashir.cda@buk.edu.ng +2348039728221
}

\begin{abstract}
Mint herbs have been reported to possess several biological effects, and the dried leaves are traditionally used for herbal tea or medicine. Extraction of plant materials was by maceration method. Both preliminary qualitative screening of phytochemicals and Liquid Chromatography Mass Spectrometer (LCMS) profiling revealed many useful metabolites. The phytochemicals include: Saponin, Carbohydrate, Alkaloids, Cardiac glycoside, and Steroid. Some LCMS compounds among others were also evaluated such as Quassin, Epioxylubimin, furocoumarinic acid glycoside and Dioctylamine. The antimicrobial activity of Mentha piperita extract against some food-borne pathogens such as Escherichia coli, Salmonella spp., Enterobacter spp. and Staphylococcus aureus were evaluated using agar well diffusion method at different concentrations ranging from 2000 $\mu \mathrm{g} / \mathrm{ml}-250 \mu \mathrm{g} / \mathrm{ml}$. The results revealed that hexane mint extracts had activity against the bacterial isolates. The highest activity was against $E$. coli $(11.50 \pm 1.50)$ while the least activity was against Enterobacter spp $(6.14 \pm 0.13)$. The potential bioactive metabolites identified could be responsible for the antimicrobial activities observed. These findings have thus proven that Mentha piperita is more effective against $E$. coli. Therefore this extract could be used in the control and prevention of many food-borne pathogens and can be of importance in developing new biopreservatives.

Kev words: Metabolite, phvtochemical, Mint. Antimicrobial, Pathogen.
\end{abstract}

\section{INTRODUCTION}

Plants have always been a good source of medicine and have been used from time immemorial to heal various ailments (Natarajan et al., 2003). The genus Mentha belongs to the Lamiaceae family, which include many species that differ widely in characteristics and cytogenetics (Ali et al., 2002). The fresh leaves (Mentha piperita) are commonly used as a raw vegetable or flavoring herb, whereas the dried leaves are traditionally used for herbal tea or medicine (Natarajan et al., 2003). Mint (Mentha piperita) is a perennial herb with a unique aroma and colourful history. Mentha piperita has been reported to be used internally as tea, tincture, oil or extracts, and externally as rub or liniment (Sujana et al., 2013). Mint herbs have been documented to possess several biological effects, including antioxidant, anti-inflammatory, anticancer, and antimicrobial activities (Wang et al., 2018). The antioxidant activity of this plant exclusively relies on its chemical composition and can prevent oxidative stress at the cellular level or in a living organism. Other studies have reported the use of mint extract as an antioxidant and antimicrobial bioactive natural extract (Wang et al., 2018). Many studies have revealed the inhibitory ability of this plant depending on the type of bacteria and its strong antimicrobial ability against Grampositive bacteria, especially S. aureus (Talei et al., 2017). Phytochemicals generally have biological activity in the plant host and play a role in plant growth or defence against competitors, pathogens or predators (Molyneux et al., 2007).

Due to failure of some certain antibiotics to deliver a therapeutic potential and high cost, most especially in low income or developing nations, there is need to search for an alternative source of therapeutics particularly from plant and to evaluate its metabolite contents using sensitive tool like Liquid Chromatography Mass Spectrometer ( LCMS). Therefore this study is aimed to determine the antimicrobial activity of Mentha piperita leave Hexane extract onsome food pathogens and identify its LCMS profile. 


\section{MATERIALS AND METHODS}

Collection of Plant Materials

Fresh mint leaves were obtained commercially from Bakin dogo market, Kaduna, Nigeria. It was taken to herbarium unit of Biological Sciences Department of Bayero University Kano, where it was identified and a voucher specimen no. BUKHAN 337 deposited. The leaves were washed first under running tap water and dried at room temperature in dark. It was then grinded into smooth powder and kept in clean polythene nylon as reported by Modupe et al. (2017).

\section{Extraction of Mentha piperita leaves}

The Mentha piperita leaves were extracted using hexane as reported by Modupe et al. (2017). Forty grams $(40 \mathrm{~g})$ of the plant material was soaked in $200 \mathrm{ml}$ of solvent (Hexane). The mixture was left for 48 hours, and then it was filtered using a nylon sieve. The extract was evaporated and kept labelled as the hexane extract.

Phytochemical Analysis

Mentha piperita leave extracts was used for preliminary qualitative screening of phytochemicals as per standard biochemical procedures. The crude extract was diluted with hexane to the concentration of $1 \mathrm{mg} / \mathrm{ml}$. The qualitative phytochemical analysis of crude hexane mint leave was conducted to determine the presence of secondary metabolites (Tannins, Saponins, Flavonoids, Alkaloids, Steriods, Cardiac glycosides and Anthraquinone) (Modupe et al., 2017).

Liquid Chromatography Mass Spectrometry (LCMS) Profile Analysis

The samples were analysed using liquid chromatography (LC) tandem mass spectrophotometer (MS) as described by (Piovesana et al., 2018) with some modifications. The extracted samples were reconstituted in Methanol and filtered through polytetrafluoroethylene (PTFE) membrane filter with $0.45 \mu \mathrm{m}$ size. After filtration, the filtrate $(10.0 \mu \mathrm{l})$ was injected into the LC system and allowed to separate on Sunfire C18 5.0um $4.6 \mathrm{~mm} \times 150 \mathrm{~mm}$ column. The run was carried out at a flow rate of $1.0 \mathrm{~mL} / \mathrm{min}$, Sample and Column temperature at $25^{\circ} \mathrm{C}$. The mobile phase consists of $0.1 \%$ formic acid in water (solvent $A$ ) and $0.1 \%$ formic acid in Acetonitrile (solvent $B$ ) with a gradient as in Table 1:

Table 1: Solvent Gradient

\begin{tabular}{ccc}
\hline Time & $\%$ A & $\%$ B \\
\hline 0 & 95 & 5 \\
1 & 95 & 5 \\
13 & 5 & 95 \\
15 & 5 & 95 \\
17 & 95 & 5 \\
19 & 95 & 5 \\
20 & 95 & 5 \\
\hline
\end{tabular}

From ratio of $A / B$ 95:5 this ratio was maintained for further 1 min, then $A / B$ 5:95 for $13 \mathrm{~min}$, to $15 \mathrm{~min}$. then A/B $95: 5$ to $17 \mathrm{~min}, 19 \mathrm{~min}$ and finally $20 \mathrm{~min}$. the Photodiode Array (PDA) detector was set at $210-400 \mathrm{~nm}$ with resolution of $1.2 \mathrm{~nm}$ and sampling rate at 10 points/sec. The mass spectra were acquired with a scan range from m/z $100-1250$ after ensuring the following settings: ESI source in positive and negative ion modes; capillary voltage $0.8 \mathrm{kv}$ (positive) and $0.8 \mathrm{kv}$ (negative); probe temperature $600^{\circ} \mathrm{C}$; flow rate $10 \mathrm{~mL} / \mathrm{min}$; nebulizer gas, $45 \mathrm{psi}$. MS set in automatic mode applying fragmentation voltage of $125 \mathrm{~V}$. The data was processed with Empower 3 . The compounds were identified on the basis of the following information, elution order, and retention time (Rt), fragmentation pattern, and Base peak $\mathrm{m} / \mathrm{z}$ (Piovesana et al, 2018)

Isolation of Microorganisms from Gurasa

Food pathogens such as Salmonella spp., E. coli, Enterobacter spp. and Staphylococcus aureus were grown and isolated from gurasa as described by Jideani, (2003). Twenty-five (25g) of homogenized sample was aseptically weighed and dissolved in sterile $225 \mathrm{ml}$ of buffered in a $500 \mathrm{ml}$ conical flask to obtain a ratio $1: 10$. One $(1 \mathrm{ml})$ of the homogenate was introduced into a test tube containing $9 \mathrm{ml}$ of the buffered peptone water and labelled $10^{-1}$ dilution and serially diluted into four test tubes labelled $10^{-2}, 10^{-3}, 10^{-4}$ and $10^{-5}$
Pour plate method was used for plating the samples. One $(1 \mathrm{ml})$ from the dilution $10^{-5}, 10^{-4}$ and $10^{-3}$ were taken using sterile syringe and then it was introduced into sterile petri dish, these were done in duplicate for the food sample. The prepared media were poured into the Petri dishes containing $1 \mathrm{ml}$ of diluted culture. The plates were swirled to mix properly. All plates were allowed to solidify and incubated at $37^{\circ} \mathrm{C}$ for 24 hours as reported by Mbajiuka et al. (2014). 


\section{Viable plate count}

Colony counting machine was used for counting the total aerobic bacteria contained on each plates (Mbajiuka et al., 2014)

\section{Gram staining technique}

Smear of each isolate was made on the slide and heat fixed. Primary stain (crystal violet) was applied for 45 second and washed with gentle running water. Lugol's iodine was added for 45 seconds and was decolorized with acetone - alcohol and washed with clean water. The slides were counter stained with $30 \%$ safranin for 30 second and washed. It was then air dried and examined at under oil immersion lens of the microscope used (Cheesbrough, 2006).

\section{Biochemical Tests}

Different biochemical tests such as catalase, coagulase, oxidase, indole, urease, methyl red, voges-proskauer and citrate utilization test were conducted in order to further characterize the organisms as described by cheesbrough, (2006).

Preparation of different Concentrations of the plant extract

Stock solution of concentration $2000 \mu \mathrm{g} / \mathrm{ml}$ was prepared by dissolving $2 \mathrm{~g}$ of the plant extracts in $1 \mathrm{ml}$ of dimetyhyl sulphoxide (DMSO) in glass vial bottles as reported by Cheesbrough (2006). And then diluted to have varied concentrations $(2000 \mu \mathrm{g} / \mathrm{ml}, 1000 \mu \mathrm{g} / \mathrm{ml}, 500 \mu \mathrm{g} / \mathrm{ml}$ and $250 \mu \mathrm{g} / \mathrm{ml}$ ).

\section{Standardization of Inoculum}

The isolates were adjusted to 0.5 McFarland standard $\left(1.5 \times 10^{8} \mathrm{CFU} / \mathrm{ml}\right)$ using sterile normal saline. McFarland standards were used as a reference to adjust the turbidity of microbial suspension so that the number of microorganisms will be within a given range. For the preparation of the 0.5 McFarland standard, $0.05 \mathrm{ml}$ of barium chloride $\left(\mathrm{BaCl}_{2}\right)$ $\left(1.17 \% \mathrm{w} / \mathrm{v} \mathrm{BaCl}_{2} .2 \mathrm{H}_{2} \mathrm{O}\right)$ was added to $9.95 \mathrm{ml}$ of $0.18 \mathrm{M} \mathrm{H}_{2} \mathrm{SO}_{4}(1.0 \% \mathrm{~W} / \mathrm{v})$ with constant stirring. To aid comparison the standard was compared against a white background with a contrasting black line (Kalpana et al., 2013).

Antimicrobial Assay:

The bioassay was carried out using the agar well diffusion method described by Cheesbrough (2006). $0.1 \mathrm{ml}$ of the standardized inoculums $\left(1.5 \times 10^{8} \mathrm{CFU} / \mathrm{ml}\right)$ of the isolated organisms was inoculated onto sterile prepared Mueller Hinton Agar and was spread with a sterile swab. Five wells were made with a $6 \mathrm{~mm}$ sterile cork borer into the agar plates containing the bacterial inoculums and $0.1 \mathrm{ml}$ of the four different concentrations from the stock solution of the extracts at concentrations (2000, 1000, 500, and $250 \mu \mathrm{g} / \mathrm{ml}$ ) were introduced into their respective wells. $0.1 \mathrm{ml}$ of $250 \mu \mathrm{g} / \mathrm{ml}$ of sodium benzoic acid was introduced into the fifth well to serve as a positive control for the bacterial isolates. The inoculated plates were left to stand for about 30 minutes to allow diffusion of extract before incubating at $37^{\circ} \mathrm{C}$ for 24 hours. The zones of clearance produced around the wells after incubation was observed and measured using a Vernier calliper and recorded $(\mathrm{mm})$. Each of the experiment was conducted twice and the mean result was taken for the test organisms.

\section{Determination of Minimum Inhibitory Concentration and Minimum Bactericidal concentration:}

The minimum inhibitory concentration (MIC) is defined as the lowest concentration of the antimicrobial agent that inhibited visible growth of microorganisms after overnight incubation (Andrews, 2002). The doubling micro dilution broth method was used to determine the MIC. Two $(2 \mathrm{ml})$ millilitres of the reconstituted crude extract at a concentration of $1000 \mu \mathrm{g} / \mathrm{ml}$ was added to $2 \mathrm{ml}$ of sterile Mueller Hinton broth for the bacterial isolates, Two (2ml) millilitres of this extract concentration was transferred serially into test tubes numbered 1-9 until the 10th test-tube was reached, giving extract concentrations ranging from $1000-65.2 \mu \mathrm{g} / \mathrm{ml} .0 .1 \mathrm{ml}$ of an $18 \mathrm{~h}$ culture of bacteria previously adjusted to 0.5 McFarland standard was inoculated into each of the test tubes and the contents were thoroughly mixed. A test tube containing the broth and bacteria inoculum was used as negative control. The inoculated culture tubes were incubated at $37^{\circ} \mathrm{C}$ and observed for growth after 24 hours. The lowest concentration of extract showing no visible growth when compared with the control was considered as the MIC as demonstrated by Andrews (2002).

The minimum bactericidal concentration:

This is the lowest concentration of antimicrobial agent that prevented the growth of an organism. $0.1 \mathrm{ml}$ aliquot from the tubes that showed no visible bacterial growth from the determination of minimum inhibitory concentration was inoculated on a sterile Mueller Hinton Agar for 24 hours at $37 \circ \mathrm{C}$ for the bacterial isolate. The lowest concentration in which no growth occurred was taken as the minimum bactericidal concentration (MBC) as demonstrated (Andrews, 2002). 
RESULTS

The preliminary phytochemical screening of Mentha piperita hexane extract (table 2) indicated the presence of saponins, carbohydrates, alkaloids, cardiac glycosides and steroids while tannins and flavoniods were absent.

Table 2: Phytochemical Screening of Mentha Piperita Hexane leave extract

\begin{tabular}{lcc}
\hline & Test & Hexane Mint Extract \\
\hline Saponins & & + \\
Tannins & & - \\
Carbohydrates & & - \\
Flavonoids & + \\
Alkaloids & + \\
Cardiac glycosides & & + \\
Steroids & & + \\
\hline
\end{tabular}

Key: HME- Hexane mint extract, + = positive, - =negative

Compounds such as Epioxylubimin, Furocoumarinic acid glycoside, Quassin (Quassinoids) and Dioctylamine (Dialkylamines) were identified from the LCMS profiling studies as reported in table 3. Both the total chromatogram and fragmentations of the identified metabolites are also presented in figures 1-5 respectively.

Table 3: Liquid chromatography mass spectrometry Profile of Mentha piperita Hexane Extract

\begin{tabular}{llcc}
\hline Peak & Tentative compounds & molecular mass $(M)$ & $M Z(M+H)$ \\
\hline 1 & Epioxylubimin & 269 & 270 \\
2 & Furocoumarinic acid glycoside & 366 & 367 \\
3 & Quassin (Quassinoids) & 388 & 389 \\
4 & Dioctylamine (Dialkylamines) & 241 & 242 \\
\hline
\end{tabular}

Key: LCMS- Liquid chromatography mass spectroscopy, MZ - Mass to charge ratio

The antimicrobial potential of hexane Mentha piperita leave extract was presented in table 4. The results revealed the potency of this plant extract against some food pathogens.

Table 4: Antimicrobial Activity of Mentha piperita Extract on Food Pathogens

Organisms zone of inhibition $(\mathrm{mm})$

\begin{tabular}{llllll} 
Conc. $(\mu \mathrm{g} / \mathrm{ml})$ & 2000 & 1000 & 500 & 250 & 250 \\
Staph. aureus & $10.5 \pm 0.5$ & $8.5 \pm 0.5$ & $6.5 \pm 0.5$ & $6.0 \pm 0$ & $7.5 \pm 0.5$ \\
Salmonella spp. & $9.0 \pm 0$ & $7.5 \pm 0.5$ & $6.6 \pm 0.4$ & $6.0 \pm 0$ & $7.5 \pm 0.2$ \\
E. coli & $11.5 \pm 1.5$ & $8.0 \pm 1.0$ & $6.5 \pm 0.5$ & $6.0 \pm 0$ & $11.0 \pm 3$ \\
Enterobacter spp. & $6.14 \pm 0.13$ & $6.00 \pm 0$ & $6.00 \pm 0$ & $6.00 \pm 0$ & $8.0 \pm 0$ \\
\hline
\end{tabular}

Key: Control (sodium benzoic acid)

The Minimum Inhibitory Concentration and Minimum Bactericidal Concentration of the hexane mint extract indicates that the MIC can reduce the growth of most of the microorganisms used in this studies drastically or eliminate it completely except for Enterobacter spp.

Table 5: Minimum Inhibitory Concentration and Minimum Bactericidal Concentration of Hexane Mentha piperitaExtract $(\mu \mathrm{g} / \mathrm{ml})$

\begin{tabular}{lcc}
\hline Organisms & HME $(M I C)$ & HME $(M B C)$ \\
\hline Salmonella & 125 & 125 \\
Staph. aureus & 62.5 & 0 \\
E. coli & 62.5 & 62.5 \\
\hline
\end{tabular}

Key:HME- Hexane mint extract, 


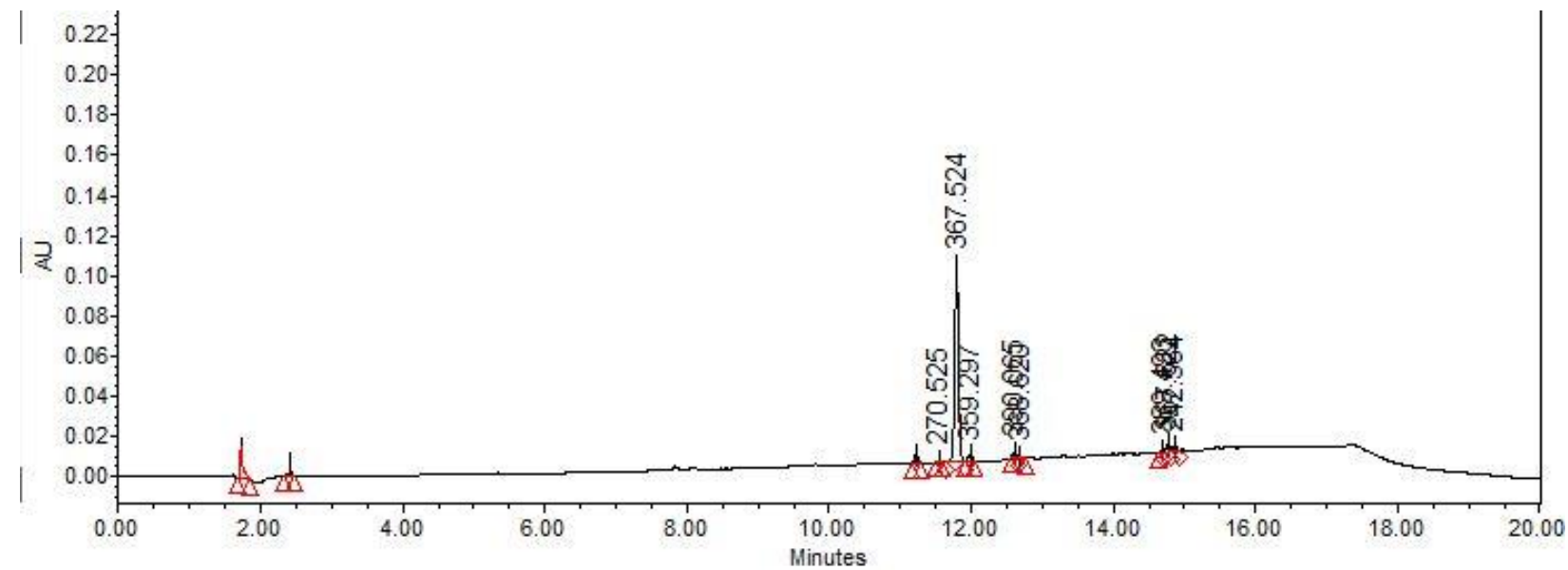

Figure 1: Total Chromatogram of the Hexane extract of Mentha peperita leave

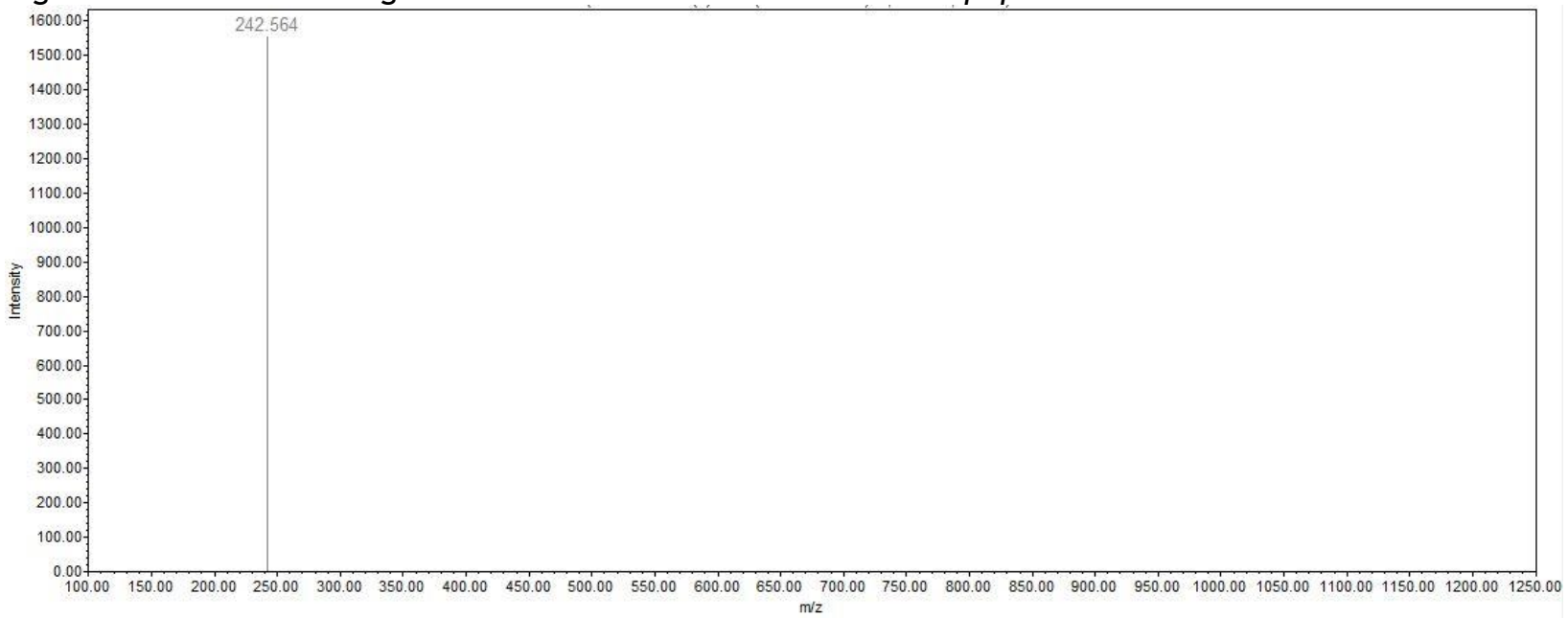

Figure 2: Mass fragmentation of Dioctylamine (Dialkylamines) (242.564 mz)

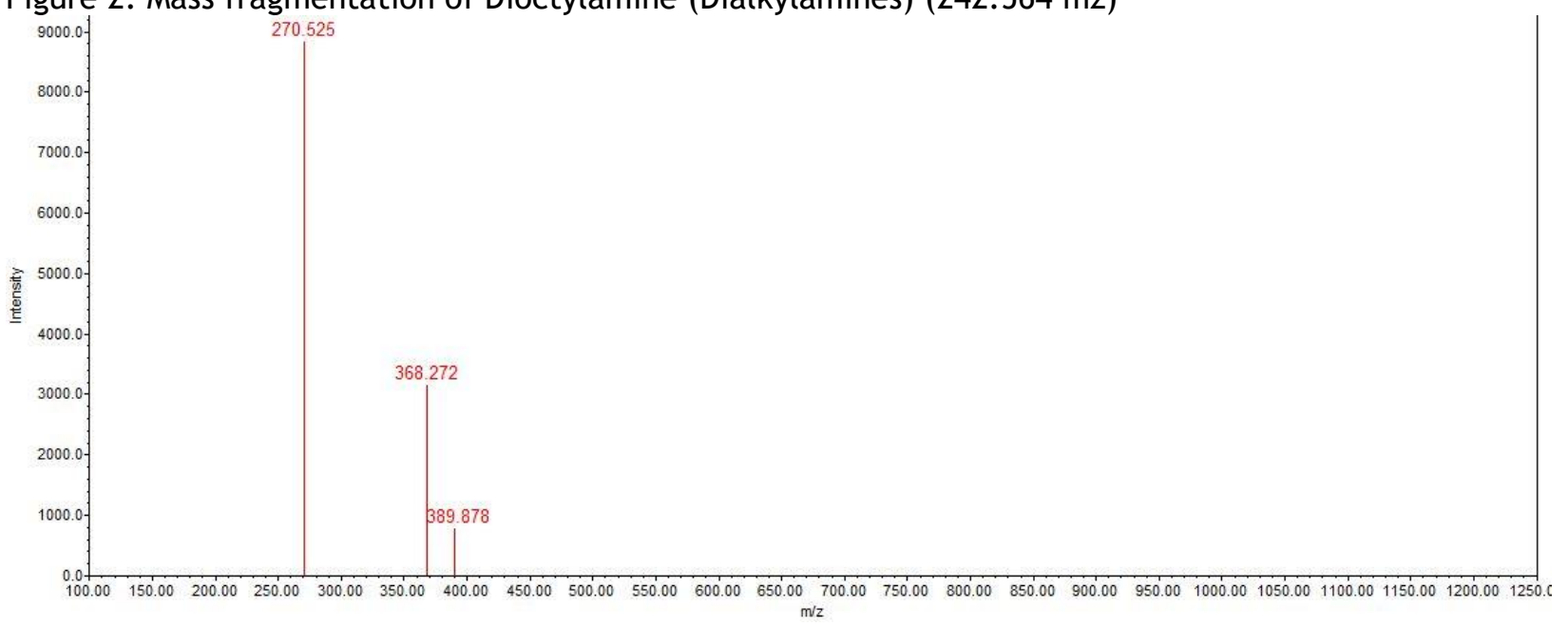

Figure 3: Mass fragmentation of Epioxylubimin $(270.525 \mathrm{mz})$ 


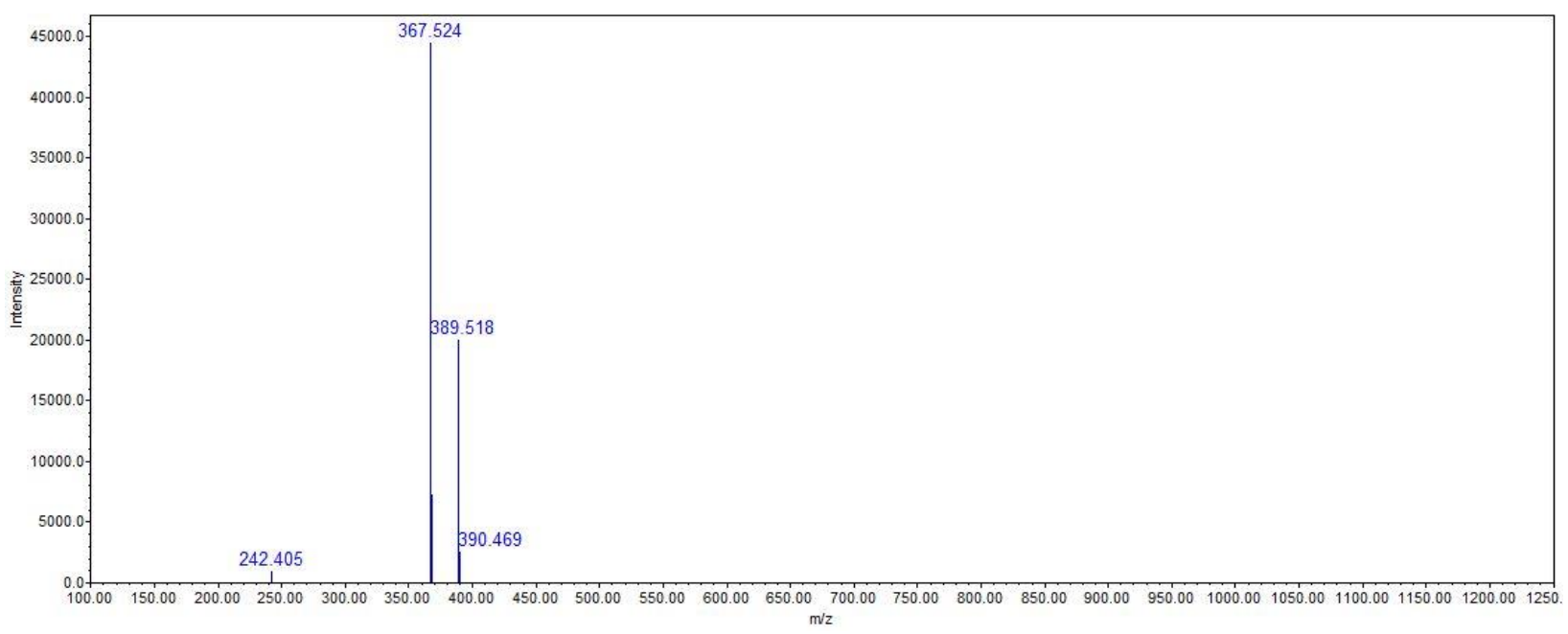

Figure 4: Mass fragmentation of Furocoumarinic acid glycoside (367.524 mz)

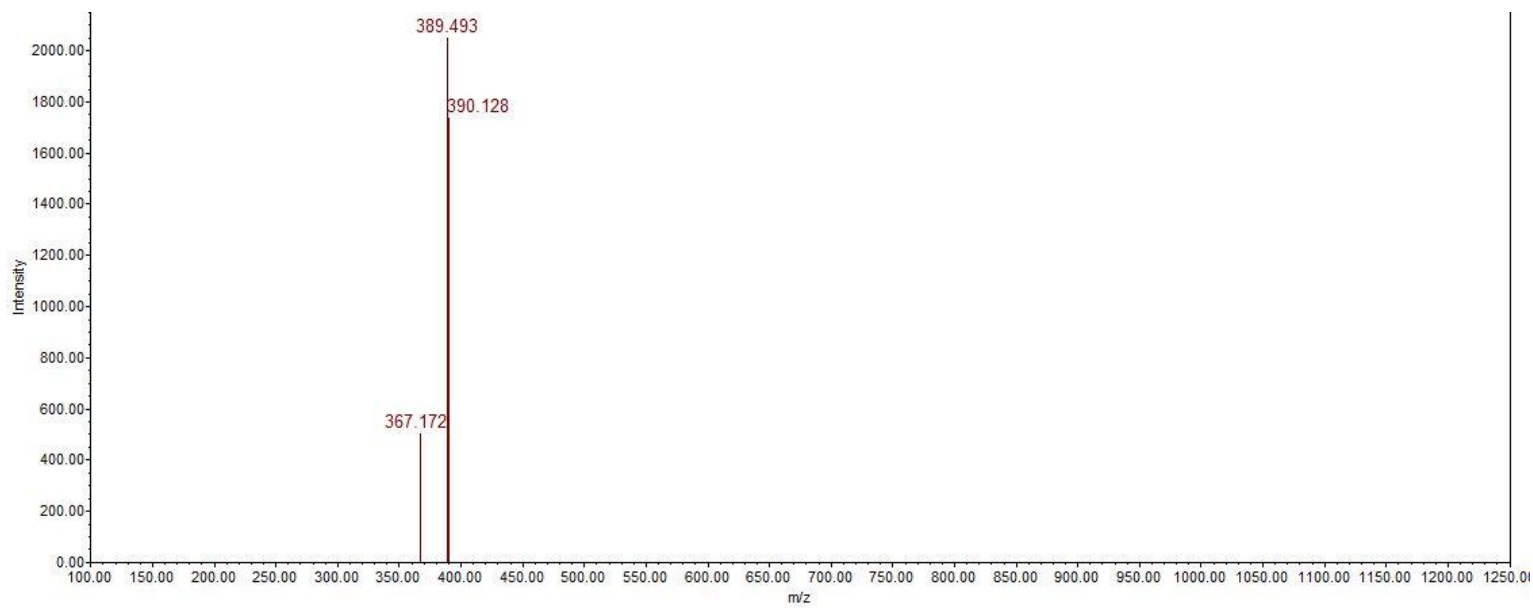

Figure 5: Mass fragmentation of Quassin (Quassinoids) (389.493 mz)

\section{DISCUSSION}

The present study revealed the presence of phytochemicals such as saponins, carbohydrates, alkaloids, cardiac glycosides and steroids while tannins and flavonoids were absent. This is in agreement with the work of Sujana et al (2013) who reported the presence of steroids and absence of tannins the leave hexane extract of Mentha piperita. But in contrast with the work of Sontakke and Shinde (2019) who reported the presence of saponins, carbohydrates, alkaloids, terpenoids, steroids ,tannins, phenols and flavonoids in the leave hexane extract. This could be due to the differences of geographical origin of Mentha piperita, moreso, Farooq et al. (2007) reported that plants occuring in varying habitats will have variation in the concentration and composition of phytochemicals in the different parts of such plants. Previous literatures have emphasized on the contribution of phytochemicals in antimicrobial and therapeutic properties, so this plant is expected to have many medicinal uses (Kaur et al., 2010). The LCMS profile of the Hexane extract of mint indicate the presence of vital metabolites: (Epioxylubimin, Furocoumarinic acid glycoside, dioctylamine and Quassin (Quassinoid) which were identified based on their molecular fragmentation pattern and compared to a data base for organic compounds (SDBS data base for organic compound). .Most of these compounds were reported severally in previous researches to be responsible for antibacterial activities against microorganisms such as Staphylococcus aureus (Matsuura et al., 2007; Shumaila et al., 2021).

The antimicrobial activity of Hexane mint extract revealed that, the extract inhibited the pathogens with the highest zone of inhibition of $11.5 \pm 0.5,10.5 \pm 0.5$ and $9.0 \pm 0$ against $E$. coli, staphylococcus aureus and salmonella spp. respectively. However higher zones were obtained with methanol mint extracts reported by Sujana et al. (2013), which could be as a result of polarity differences. Therefore the antimicrobial activity observed in this study may be as a results of these phytochemical constituents as well as the vital LCMS metabolites. 
The MIC and MBC of the hexane Mentha piperita extract indicated that the MIC that inhibited or retarded the growth of the pathogens also killed them completely except for Staphylococcus aureus which was inhibited at a concentration of $62.50 \mu \mathrm{g} / \mathrm{ml}$ only. This indicates that Mentha piperita could have both bacteriostatic and bactericidal properties on pathogens.

\section{CONCLUSION}

The findings of this work revealed that Mentha piperita leave extracthas potential bioactive phytochemicals such as saponins, carbohydrates, alkaloids, cardiac glycosides and

\section{REFERENCES}

Ali, M.A., Saleem, M., Ahmad, W., Parvez M. and Yamdagni, R. (2002). A chlorinated Monoterpene Ketone, AcylatedSitosterol Glycosides and a Flavanone Glycoside from Mentha logifonia (Lamaceae)," Phytochemistry 59 (8) 889 - 595.

Andrews, J.M. (2002). Determination of minimum inhibitory concentration. J. Antimicrob. Chemother. 48: 5-16.

Cheesbrough M. (2006). District laboratory practice: In tropical countries. Part 2, 2nd ed. USA: Cambridge University press

Farooq, A., Sajid, L., Muhammad, A. and Anwarul Hassan, G. (2007): Moringa oleifera: a food plant with multiple medicinal uses. Phytotherapy Research. $21: 17-25$.

Jideani S (2003) Cost effectiveness of a targeted disinfection program in household kitchens to prevent food borne illness in the United states, Canada and the United Kingdom. Journal of food protection 66(11): 2103-2115.

Kalpana, S., Moorth, S. and Sushila, K. (2013). Antimicrobial activity of different extracts of leaf of Moringa oleifera (Lam) against gram positive and gram negative bacteria. Department of Biochemistry, Asan memorial college of Arts and Science, Chennai, India. Int. J. Curr. Microbiol. App. Sci 2(12): 514518.

Kaur, K., Wadhwa, M., and Bakshin, M.P.S. (2010). Nutritional evaluation of pleurotus florida harvested spent wheat-rice straw based diets in goats. Indian J. Anim. Sci., 80 (8) 750-753.

Matsuura H., Takahashi K., Nabeta K., Yamasaki M., Maede Y., and Katakura K., (2007) . Screening of Indonesian Medicinal plant

UMYU Journal of Microbiology Research steroids that could be responsible for the antimicrobial activities observed, and it was supported with the results of the LCMS profile that revealed the presence of Epioxylubimin, Furocoumarinic acid glycoside, dioctylamine and Quassin (Quassinoid . Additionally some of the metabolites identified have been previously reported to be responsible for antimicrobial activity and other medicinal potentials. Therefore it can be concluded that hexane extract of Mentha piperita can be useful in the control and prevention of many food-borne pathogens and can be of importance in developing biopreservatives.

Extracts for Antibabesial Activity and Isolation of New Quassinoids from Brucea Javanica . J. Nat. P. 70 (10), 1654-1657.

Mbajiuka, C.S, Obeagu El, and Ifediora A.O. (2014). Isolation and identification of microorganisms involved in the spoilage of soymilk. IOSR Journal of Pharmacy and Biological Sciences volume; 9(5):29-36.

Modupe, E.O., Samuel OA., Oladele J.O., Esther A.O.,Olabenga S.T., and Emmanuel 0.0. (2017). Phytochemical and antimicrobial activities of leaf oil extract of Mentha spicata and its efficacy in repelling mosquitoes. International journal of pharmaceutical research and allied sciences 6(4):17-27.

Molyneux, R.J; Lee, S.T; Gardner, D.R; Panter, K.E and James, L.F. (2007) "Phytochemicals: the good, the bad and the ugly?"Phytochemistry. 68 (22-24), 2973-85.

Natarajan, V., Venugopal, P.V., and Menon, T. (2003). Effect of azadirchta indica (neem) on growth pattern of dermatophytis. Indian Journal Medicinal Microbiology 21(2): 98 - 101.

Piovesana, A., Rodrigues, E. and Norena, Z. (2018). Composition analysis of carotenoids and phenolic compounds and antioxidant activity from Hibiscus calyces (Hibiscus sabdariffa $\mathrm{L}$ ) by HPLCDAD-MS/MS. Phytochemical Analysis, 435, $1-10$.

Sontakke, K.S. and Shinde, S.L. (2019). Phytochemical screening and evaluation of In-vitro antimicrobial properties of Mentha piperita L. Int. J. of life Sciences, 7(4) 785-790 
Sujana,P., Sridhar,T. M.,Josthna, P., and Naidu, C.V. (2013). Antibacterial activity and phytochemical analysis of Mentha piperital. (peppermint). An important multipurpose medicinal plant. American Journal of Plant Sciences. 4: 77 - 83.

Talei, G.R.; Mohammadi, M.; Bahmani, M.and Kopaei, M.R. (2017). Synergistic effect of Carum copticum and Mentha piperita essential oils on Gram-negative and Gram- positive bacteria. Int $J$ pharm. 7(2): $82-87$
Wang, H., Xie, M., Charpin-El Hamri, G., Ye, H., and Fussenegger, M. (2018). Treatment of chronic pain by designer cells controlled by spearmint aromatherapy. Nat. Biomed. Eng. 2, 114-123. doi: 10.1038/s41551-018-01923. 